\title{
Children's Perceptions of Pain in Conjunction With Tooth Extraction - A Grounded Theory Study
}

Henrik Berlin ( $\square$ henrik.berlin@mau.se )

Malmö University

Ulrika Hallberg

Malmö University

Karin Ridell

Malmö University

Danijela Toft

Colosseum Smile Dental Group

Gunilla Klingberg

Malmö University

\section{Research Article}

Keywords: child, adolescent, dental care, pain, grounded theory

Posted Date: June 24th, 2021

DOI: https://doi.org/10.21203/rs.3.rs-612357/v1

License: (c) (1) This work is licensed under a Creative Commons Attribution 4.0 International License. Read Full License 


\section{Abstract}

Background: Children frequently experience pain/discomfort during dental treatment. At the same time there seems to be uncertainty among dentists regarding pain management. Pain research in dentistry has mainly been performed in adults using quantitative methods. Meanwhile, qualitative methods as well as the child's perspective are scarce. This study aims to explore and describe children's experiences/thoughts regarding pain in conjunction with tooth extraction and the subsequent postoperative period, using grounded theory (GT).

Methods: Qualitative interviews were carried out with twelve 10-16-year-olds. Interviews were transcribed verbatim and analysed in open, as well as focused (selective) coding processes according to GT. Three informants were re-interviewed for verification purpose.

Results: A core category was identified and named 'handling the unavoidable unknown'. Instead of focusing on pain, the informants described an urge for more information about the procedure and what to expect in terms of pain/discomfort, during and/or after treatment. They stated that the levels of pain/discomfort were manageable, while the lack of information negatively affected their coping abilities, causing anxiousness.

Conclusions: To improve patients' ability to deal with pain in conjunction with dental extraction, the dental team should ensure better information about the treatment. Thus, the use of psychological techniques is a cornerstone in pain management and must be reflected in clinical guidelines.

Trial registration: This study's protocol was registered on ClinicalTrials.gov (NCT04064853), August 22, 2019, available at https://clinicaltrials.gov/ct2/show/NCT04064853?

term=berlin\&cntry $=S E \& d r a w=2 \&$ rank $=1$

\section{Introduction}

Pain and discomfort are relatively common among children receiving dental treatment, with some procedures perceived as being more painful than others. Pain after tooth extraction was investigated in a study on pain's natural course (1) where $28 \%$ of the extractions $(16 / 57)$ resulted in moderate pain or worse. Another study reported that approximately one third of children experience pain and/or discomfort in conjunction with treatment occasions (2). Despite the high frequency of pain reports, there seems to be uncertainty among Swedish dentists regarding pain management when treating children and adolescents (3). Pain management should include both non-pharmacologic and pharmacologic methods and be scientifically based. The effectiveness of local anaesthesia is well known, while that of oral analgesics has been less investigated. In 2016, an updated Cochrane-review could not show enough scientific evidence to conclude if preoperatively administered oral analgesics had any reducing/preventing effect on postoperative pain after dental treatment under local anaesthetics (4). There is also a lack of evidence regarding postoperatively administered oral analgesics for preventing/reducing postoperative pain (5). Much of the lack of evidence concerns a shortage of well-designed randomised controlled studies. It is 
difficult to perform pain studies in children for several reasons, not least ethics. One important aspect is also the scarceness of children's points of view regarding dental pain, which needs to be explored before designing these kinds of studies.

Pain is defined as 'an unpleasant sensory and emotional experience associated with actual or potential tissue damage, or described in terms of such damage' (6). Due to pain's subjective nature (6), it can be difficult to measure pain objectively and patient-centred self-report instruments are therefore advocated (7). Much of the performed research in dentistry has used quantitative methods, which is important for collecting and generalising objective knowledge. One important aspect might however be lost using quantitative methods, namely the subjective perspective of the individuals participating in the study. The child's experience and understanding of how she/he feels should position the child as an expert, but all too often does not (8).

The aim of this study was to explore and describe, using grounded theory, children's experiences and thoughts of pain in conjunction with tooth extraction and the subsequent postoperative period. Knowledge about these concepts could serve as a basis for future studies, which is a prerequisite to be able to formulate guidelines on pain management for dental personnel treating children and adolescents when there is a risk of pain.

\section{Materials And Methods}

\section{Study group and procedure}

Identification of eligible participants was made during their visits to any of the private orthodontic clinics in Malmö, Sweden. The orthodontists had received an informational letter about the study, stating the inclusion and exclusion criteria along with written information for potential participants and their legal guardians. The orthodontist gave written and verbal information to the potential candidate and his or her legal guardian. The legal guardian signed an informed consent form, which was sent to one of the authors of this article (HB). All children received age-appropriate information and assented to participate. The Swedish Ethical Review Authority, Sweden (\# 2019 - 00121, (2018/1029)) approved the study. Inclusion criteria for the potential participants were: children aged 10-16 requiring extraction of premolars prior to orthodontic treatment, in good general health. The exclusion criterion was if the patient or legal guardian could not understand Swedish. The protocol for this study was registered on ClinicalTrials.gov (NCT04064853), August 22, 2019, available at https://clinicaltrials.gov/ct2/show/NCT04064853?term=berlin\&cntry=SE\&draw=2\&rank=1.

The informants were contacted to schedule a time and place for the interview at least one week after tooth extraction. The interviewer was not known to the participants in advance and did not take part in their dental treatments. We included 12 informants, 10-16-year-olds, all living in the southern parts of Sweden. There were five girls (mean 13.0 years old) and seven boys (mean 14.6 years old). The study group was strategically selected in terms of sex, age, and residence (type of housing to mirror 
socioeconomic background). We also ensured to include informants having experience of both one and two extractions, but also recently initiated orthodontic treatment. According to grounded theory, a strategic sampling of participants is recommended to obtain a heterogeneous group and to maximise the variations of experiences in the studied group (9). After the first five interviews, informants were identified more strategically to ensure that all aspects of the background were included. Their previous experiences from dental treatments varied; however, the informants had in general had few previous experiences with local anaesthetics.

First, eleven interviews were performed and analysed, then three informants were re-interviewed, and finally a twelfth informant was included for verification purpose.

\section{Method}

The constant comparative method for grounded theory, described by Glaser \& Strauss (9), and advanced by Strauss \& Corbin (10), and Charmaz (11), was used for data collection and analysis in this study. The modified version of grounded theory argues that reality cannot be fully known but can always be interpreted. Strauss \& Corbin's version of grounded theory (10) takes a more post-positivistic position, focusing on social processes (12). Classical grounded theory (9) describes the phenomenon under study as a main concern for the informants that has to be solved. Its ontological position is close to positivism due to its adoption that a 'real reality' can be discovered and described without any influence from the 'objective' researcher (12). In classical grounded theory, to be able to solve the main concern, informants use different strategies that are described in different categories. In the various versions of grounded theory, the aim is to make meaning explicit by generating concepts, models, or theories that are grounded in empirical data. The basic principles of grounded theory include theoretical sampling and hierarchical analysis, constant comparisons, theoretical sensitivity, and saturation. Theoretical sampling is used to reach saturation and is guided by the emerging categories (10). Saturation, although somewhat 'elastic', is reached when new interviews do not bring additional information to the emerging categories, i.e. when new data fit into the categories already devised (10). Theoretical sensitivity refers to the researcher's reflexive way of developing research questions and doing analysis. Grounded theory is rooted in symbolic interactionism and includes that meaning is constructed and changed through interactions between people (11). Accordingly, perceptions of the world are individual and constantly changed by individuals' interaction with it (13).

\section{Qualitative interviews}

Data were collected from April 2019 to April 2021. So-called open interviews lasting 30 to 45 minutes were conducted in a conversational style with each informant by the main author of this article $(\mathrm{HB}, \mathrm{a}$ paediatric dentist). All interviews were taped. The first eleven interviews were carried out either in a quiet room at the dental clinic or at the informant's home. Owing to Covid-19 regulations, the twelfth interview and the three re-interviews, were performed via telephone or Zoom. No differences in the settings other than that were introduced. These interviews were conducted in November 2020 to April 2021. 
Informants were allowed to have a legal guardian with them, if they wanted. An interview guide was used and it concerned the participants' thoughts and feeling on themes such as earlier experience of dental treatments, thoughts about the treatment, problems related to the dental treatment (pain experienced during treatment and the subsequent post-operative period). Based on these themes, the interviewer asked relevant follow-up and probing questions. During the interview, the informants were informed that they had the possibility to raise questions of relevance to themselves as well.

Qualitative interviews require active and involved engagement of both the interviewer and informant in responding, clarifying, and elaborating communication. Data were generated within this process, and the quality of the data was influenced by the trusting relationship between the researcher and the informant (14). Data collection and analysis were conducted simultaneously (9-11) and continued until new interviews did not provide additional information - until saturation was reached.

\section{Analyses of data}

The interviews were transcribed verbatim by $\mathrm{HB}$ and analysed by HB, GK (paediatric dentist) and $\mathrm{UH}$ (sociologist experienced in research in the field of odontology) in parallel, using a hierarchical coding process, i.e. open and focused (selective) coding (10). Analysis continued until saturation was achieved. By open coding, the interview transcripts included the substance of the data being captured and segmented into substantive codes, which were labelled concretely. The codes were labelled either by using the informant's words (in vivo codes), or words/concepts of the interviewer's disciplines (in vitro codes). The procedure of open coding led to grouping of substantive codes with similar content into summarising categories, which in turn were given more abstract labels than the substantive codes belonging to them. In the next phase, the axial coding process, the categories were further elaborated by identifying their properties and dimensions. Further, relationships between categories were sought and verified in the data. In the selective coding process, categories were saturated with additional information, assessed by new interview or added by re-coding previously assessed data (i.e. theoretical sampling). Analyses and preliminary findings were continuously discussed between $\mathrm{HB}$ and $\mathrm{GK}$, as well as with $\mathrm{UH}$ as an external partner. A core category was identified describing a psychosocial process and this was central to the data and could be related to other relevant dimensions/categories grounded in the data. Throughout the whole process of analysis, memos and notes were written regarding ideas, preliminary assumptions, and theoretical reflections, in order to keep track of the analysis (10).

The interview transcripts were re-contextualised in the final stage to certify that raw data supported the categories, in other words, that the categories were grounded in the data. According to Charmaz (11), the unit of analysis in a grounded theory study concerns events and actions in the data rather than the separate individuals per se. Therefore, the number of informants is less interesting than the content and quality of the data.

\section{Results}


The informants' previous experiences of invasive dental treatment (i.e. local anaesthetics, filling therapy, tooth extraction, etc.) were scarce. The common experience was regular dental check-ups. All of the participants expressed some level of worrying prior to their first tooth extraction. Despite that, no one hesitated to carry on with the planned treatment. Instead, they all reported using different coping strategies to handle the situation.

\section{Handling the unavoidable unknown}

The main concern (core category) for the children was handling the unavoidable unknown. Despite the uncertainty about the treatment procedure, and what that could lead to in terms of pain/unpleasantness during the treatment and postoperatively, the participants were 'jumping into the unknown' (solving the main concern) and went through with the treatment. The children were all well aware that the treatment was unavoidable. They went through the whole procedure with many aspects of it being unknown, nor did they have any knowledge of what to expect after the treatment in terms of pain or unpleasantness. Despite the uncertainty surrounding the whole procedure of tooth extraction, the children chose to go through with the treatment. The children reported varying degrees of anxiety before the treatment. The onset of anxiety differed, but in general, it debuted shortly before treatment, often the evening before. In order for the children to deal with the unknown, they used different types of coping strategies, which are described in the five conceptual categories that were generated in the data analysis (clinging to what I can trust, clinging onto earlier experience, striving to be in control, longing to get it over with, and looking forward to a treat) (Table 1).

'Well, then again was good informing a bit earlier that it could feel like this and, yeah - if they had examples of individuals that like, had felt it was difficult, and so they could have brought that up and like tell - oh, it's no big deal or like this is how it's supposed to feel. Just so you know a bit more cause I have never done this before so I didn't know how I would feel or how it would feel... a little... uhh... I didn't really know anything about it so that's why I took everything they said very literally. So if I felt any discomfort or anything that hurt then I should raise my hand and that's what I did. But uhh...like perhaps be more...tell more.'(ID8) 
Table 1

Core category, conceptual categories, properties, and examples of meaning units regarding 'handling the unavoidable unknown'.

\begin{tabular}{|c|c|c|c|}
\hline $\begin{array}{l}\text { Core } \\
\text { category }\end{array}$ & $\begin{array}{l}\text { Conceptual } \\
\text { categories }\end{array}$ & Properties & $\begin{array}{l}\text { Examples of meaning units (in vitro } \\
\text { codes) }\end{array}$ \\
\hline \multirow{15}{*}{$\begin{array}{l}\text { Handling } \\
\text { the } \\
\text { unavoidable } \\
\text { unknown }\end{array}$} & \multirow[t]{3}{*}{$\begin{array}{l}\text { Clinging to } \\
\text { what I can } \\
\text { trust }\end{array}$} & \multirow[t]{3}{*}{$\begin{array}{l}\text { Information is crucial in } \\
\text { order to reduce patients' } \\
\text { anxiety levels. }\end{array}$} & $\begin{array}{l}\text { Had received information on how it } \\
\text { could feel during and after injection, } \\
\text { and also afterwards. (ID6) }\end{array}$ \\
\hline & & & $\begin{array}{l}\text { Wishing for more information } \\
\text { beforehand on how it could feel. } \\
\text { Especially since no previous } \\
\text { experience from invasive treatments at } \\
\text { all. (ID8) }\end{array}$ \\
\hline & & & $\begin{array}{l}\text { Got information during treatment, step } \\
\text { by step. (ID 10) }\end{array}$ \\
\hline & \multirow{4}{*}{$\begin{array}{l}\text { Clinging } \\
\text { onto earlier } \\
\text { experience }\end{array}$} & \multirow{4}{*}{$\begin{array}{l}\text { It is important to ask } \\
\text { children about previous } \\
\text { experiences so that } \\
\text { information can be adjusted } \\
\text { individually. }\end{array}$} & $\begin{array}{l}\text { Earlier experience of tooth extraction } \\
\text { led to less anxiousness this time. (ID4) }\end{array}$ \\
\hline & & & $\begin{array}{l}\text { Less nervous prior to second } \\
\text { extraction since the procedure was } \\
\text { familiar, and what to expect from the } \\
\text { postoperative period. (ID8) }\end{array}$ \\
\hline & & & $\begin{array}{l}\text { Less nervous prior to second visit. } \\
\text { Knew what was going to happen. (ID9) }\end{array}$ \\
\hline & & & $\begin{array}{l}\text { Less nervous prior to second } \\
\text { treatment. Pain also passed more } \\
\text { quickly. (ID10) }\end{array}$ \\
\hline & \multirow[t]{5}{*}{$\begin{array}{l}\text { Striving to } \\
\text { be in } \\
\text { control }\end{array}$} & \multirow[t]{5}{*}{$\begin{array}{l}\text { Give the child a possibility to } \\
\text { take control of what is } \\
\text { doable in the dental setting. }\end{array}$} & $\begin{array}{l}\text { Got the possibility to choose if one or } \\
\text { two teeth would be extracted at the } \\
\text { same appointment. (ID2) }\end{array}$ \\
\hline & & & $\begin{array}{l}\text { Got information about stop-hand. } \\
\text { (ID3) }\end{array}$ \\
\hline & & & $\begin{array}{l}\text { Was asked if it was ok to take out one } \\
\text { more tooth, after the first had been } \\
\text { extracted. (ID7) }\end{array}$ \\
\hline & & & $\begin{array}{l}\text { Feeling a bit worried that the dentist is } \\
\text { going to do something wrong. (ID8) }\end{array}$ \\
\hline & & & $\begin{array}{l}\text { Was thinking about taking pain killers. } \\
\text { But then it did not feel necessary. } \\
\text { (ID11) }\end{array}$ \\
\hline & \multirow{3}{*}{$\begin{array}{l}\text { Longing to } \\
\text { get it over } \\
\text { with }\end{array}$} & \multirow{3}{*}{$\begin{array}{l}\text { With proper handling, the } \\
\text { child is often strong enough } \\
\text { to handle some } \\
\text { pain/unpleasantness. }\end{array}$} & $\begin{array}{l}\text { Wasn't so bad, that I felt like } \\
\text { pausing/stopping the treatment. (ID1) }\end{array}$ \\
\hline & & & It did not hurt that much... (ID2) \\
\hline & & & I take it as it comes. (ID5) \\
\hline
\end{tabular}




\begin{tabular}{|llll|}
\hline $\begin{array}{l}\text { Core } \\
\text { category }\end{array}$ & $\begin{array}{l}\text { Conceptual } \\
\text { categories }\end{array}$ & Properties & $\begin{array}{l}\text { Examples of meaning units (in vitro } \\
\text { codes) }\end{array}$ \\
\hline $\begin{array}{ll}\text { Looking } \\
\text { forward to } \\
\text { a treat }\end{array}$ & $\begin{array}{l}\text { Identify motivators for the } \\
\text { child; why treatment (and } \\
\text { possible pain/discomfort) is } \\
\text { worth it. }\end{array}$ & $\begin{array}{l}\text { Is fine with having more teeth } \\
\text { extracted. It leads to more attention } \\
\text { from mother. (ID 1) }\end{array}$ \\
& & $\begin{array}{l}\text { Feels motivated to have braces. Is } \\
\text { looking forward to it. (ID5) } \\
\text { Got a lot of praise after the treatment. } \\
\text { (ID 6) }\end{array}$ \\
\hline
\end{tabular}

\section{Conceptual categories Clinging to what I can trust}

Clinging to what I can trust was based on children clinging to things the dentist had said before, such as description of tooth extraction and what could be expected during and after the procedure in terms of pain or other types of sensations. One example is that there could be a sensation of pressure in the tissue during the injection of local anaesthetics. Clinging onto concrete information and what seemed plausible was turned into a strategy for coping with treatment and pain.

'They went through each step before they did it. She said "now we're doing the anaesthetics', 'we...' - so they said exactly where I would... where they would do the injection too. And they told me the whole time during the process what they did and told me, and listened carefully if I were to tell if I wanted to abort/stop, and I did that too when... I clapped my hands so I got more anaesthetics and stuff.'(ID1)

The participants requested an adequate amount of relevant information in order to reduce levels of anxiousness, but not make them frightened/scared.

'I thought it was good that they did not tell, because otherwise I would have been even more nervous if they had told me it would hurt.'(ID5)

\section{Clinging onto earlier experience}

Clinging onto earlier experience emerged as the children used their own previous experiences to cope with treatment and pain. Some of them had undergone this type of treatment before, which gave them confidence for the treatment they underwent in conjunction with the present study. Those children with experiences of less psychologically challenging earlier treatments felt more at ease and could find motivation from those experiences in the present treatment. In contrast, those with more challenging experiences were in need of more calming information to cope with treatment.

'I've had the syringe before. So that was nothing dangerous. I hardly felt it. Didn't really notice that they did it. So that was nice.'(ID2) 
Informants interviewed after having two premolars extracted in conjunction with this study felt less distress before the second extraction compared to the first.

'The first time I hadn't felt like that before so that was more jittery. To know what it feels like... but the second time I knew kind of what it feels like and then it was a bit easier.'(ID2)

\section{Striving to be in control}

Striving to be in control is a result of children finding ways to be in control of the situation, which makes them cope with treatment. Instructing the child to raise their hand to stop the treatment immediately, gives the child a feeling of being in control of the situation. The treatment continues only as long as the child wants/gives permission.

'The first time I did but just because... but the second time it went well. I wouldn't have needed it the first time either. But it was just to feel comfortable.'(ID3)

Being able to decide for themselves if and/or when to take oral analgesics after arriving home (to reduce or prevent pain), convinces the children that they have control over the situation which helps them to cope with subsequent pain. Regardless of whether they took oral analgesics or not, this possibility to choose gave the children a sense of self-control.

'My mother suggested it but I didn't feel the need.'(ID3)

\section{Longing to get it over with}

Longing to get it over with arose during the interviews as a category of relevance since the children often mentioned that they wanted to get the treatment over with. The wish to some extent made the children more likely to cope with pain and discomfort. It was a way to save themselves from postponing the treatment, thereby prolonging the worries and anxiety. They knew that the extractions were something they had to handle to be able to get further in their treatment plan, since they knew that this would lead to straight teeth.

'No, so - I felt more than in the upper jaw but it didn't hurt that much or I felt it wasn't that uncomfortable that I had to tell.'(ID4)

\section{Looking forward to a treat}

Looking forward to a treat emerged through informants' describing positive outcomes in the future that they were eager to reach. It could be a variety of events such as spending a day with mum, choosing what movie to watch the evening of the tooth extraction, watching some Netflix shows, or longing to get their braces. With this in mind, the informants were more motivated to endure the treatment, even when there was a little pain and/or discomfort.

'That's okay too. Because then you get more attention from mum once you get home.'(ID5) 
Analyses of the interviews from the three informants being re-interviewed and the new twelfth informant did not add any new data. Rather they reinforced already emerged core category and conceptual categories. Thus, the results remained unchanged.

\section{Discussion}

This qualitative study, using grounded theory, explored children's and adolescents' experiences of procedural and postoperative pain connected to tooth extractions. Despite a great deal of uncertainty in terms of what to expect for procedural and postoperative pain, they went through with having their teeth extracted. By using different types of coping strategies, they were handling the unavoidable unknown. All informants showed a great deal of courage by having teeth extracted (on orthodontic indications) without knowing what to expect from the treatment itself or the postoperative period, including some level of anxiety prior to treatment.

The present study shows that although the children and adolescents have different experiences from previous dental treatments, there are similar traits. These are described in the five categories (clinging to what I can trust, clinging to earlier experience, striving to be in control, longing to get it over with, and looking forward to a treat), all representing different ways of coping with the tooth extractions.

Wanting more information emerged as a central part for the informants in the present study, as an aid to cope with the tooth extractions since information given appropriately makes the procedure understandable, lowering levels of fear and anxiety. In this study, the participants expressed thoughts about the information given in conjunction with treatment. The amount of information was described as sufficient; still, informants were anxious during and after treatment. We interpret this as there being a continuous need for information, which must come at an appropriate time. The relationship between dental anxiety and pain experiences, both dental and everyday pains, is well established (15) and individually tailored information about treatment should always be a first step in the prevention of both (16). Information has to be age appropriate as well as be continuously provided throughout the whole treatment procedure. Within dental care, the 'tell-show-do' procedure is commonly practiced. When the child/adolescent is guided and gradually exposed to a procedure, this will aid future cooperation with dental treatment. Problems in a dental scenario are most likely to be prevented if time and awareness are devoted (17). Based on the present study's findings, this is important to stress. A child's first treatment must be handled with empathy and understanding from the dental/medical health personnel. Being empathetic to the patient's needs and preferences may be a key factor in establishing an effective working relationship (18) and is likely to lead to future medical/dental care being characterised by cooperation rather than by conflict from the child's perspective (19). With this also comes the patient's right not to know. We as dentists have to take notice of patients' preferences of receiving or not extensive information. Some children said in their interviews that they did not want too much information as it would lead to more worrying. In such cases, it is crucial to be aware that it is not only verbal communication that matters. Non-verbal communication also aids children visiting the dentist (20). 
Previous experiences from dental visits are used by the child as a model to predict future treatments (21). In this study, the informants seemed to have had positive to neutral experiences. The first visit within this study seemed to have a positive conditioning effect on the second visit, which has been reported by Hembrecht et al. (22), who stated the consecutive dental treatments seem to have a conditioning effect. This is supported in a study of pain's natural course after tooth extractions (on orthodontic indication) where there were no differences in pain profiles after first and second extractions (1). Dental pain and dental fear and anxiety are often seen as closely rated and intertwined and in children, cognitive and emotional development will affect the child's understanding of both as well as the ability to differentiate between them. If a child has an experience with a dental procedure that was perceived as traumatic and/or frightening, future events will be coloured by that. This first experience may also be generalised so that all coming events that remotely resemble the first frightening episode, may cause fear and anxiety (23). Having many non-traumatic dental visits is an important factor in avoiding development of dental fear and anxiety, according to the theory of latent inhibition (24-26). Exposure to several repeated successful and pain-free dental visits leads to 'vaccination' (latent inhibition). If the patient later meets a negative dental experience the likelihood of developing dental fear and anxiety is lower than if this negative experience occurs during one of the first dental visits $(24,25)$.

Being in control of the situation is an important coping strategy. This can be achieved by having the opportunity to pause the treatment with a stop signal, like raising the hand (20). The participants in the present study mentioned this repeatedly. The possibility of stopping the treatment gave the informants a feeling of control. Some tested it, even though they really did not have to. Doing so can be interpreted as them not feeling totally secure in the situation, but when they noticed that the stop hand worked, they felt safer in the situation, having better control. A stop signal is very favourable for the patient and can be easily employed in practice, leading to a lowered reported stress level even if the child does not use the stop signal (20). In a study by Rodd et al. (27), children also stated that they hoped that the dental team would listen to them and tell them what was happening. Within the theme of good communication, children wanted to feel in control, by asking the dentist to cease treatment when necessary (27).

The fourth category, longing to get it done with, is a theme that has been described in other studies as well. For example, Davies \& Buchanan (20) reported that children aged 9-11 preferred getting the treatment over and done with, compared to having a pause, which would prolong the treatment.

The fifth category, looking forward to a treat, points out that motivation can make the child accept the treatment although sometimes painful/unpleasant. The informants in the present study defined a treat in different ways. For some it was watching Netflix, while for others it could be having more quality time with their parents. It could also be an eagerness to have braces, because that meant their teeth would be aligned and aesthetically appealing. This motivator to accept treatment has been shown in other studies; for example, van Meurs et al. (28) found that $92 \%$ of the children used a strategy called 'I tell myself I have to do this because it is good for my teeth'. 
A strength with the present study is that the same person performed all of the interviews and transcriptions. By this measure, a deepened acquaintance and close knowledge of the data was achieved. Also, having a multidisciplinary team reading the transcripts and participating in analyses is a strength as it warranted different views of the information, and led to picking up nuances in the participants' stories that otherwise might have been missed $(29,30)$.

The outbreak of Covid-19 led to delay in recruitment of informants. However, re-interviewing of three earlier informants plus inclusion of a new twelfth informant were conducted a few months later than originally planned. This is a verification strategy called 'member checking'. The goal is not to make a data check, rather it is a way to perform analysis at a more abstract, and higher position in the process, make a validation of concepts and their components. This leads to a completion of data collection, and this is also ensuring commitment to the data and the analysis being made $(31,32)$. From interviews of the 12 informants and 3 re-interviews, we could clearly see that saturation was reached for each category, thanks to all interviews being lengthy and rich in information. Those who analysed the data, individually, concluded this.

In general, the pain in conjunction with tooth extraction seems to be manageable. The informants were motivated to go through with the treatment despite some pain and discomfort. Their stories instead focused on the importance of not forgetting the basis in non-pharmacologic pain treatment, namely accurate and individually tailored information about treatment as well as possible pain and discomfort both during extractions and postoperatively. It may be beneficial if more detailed information about dental extraction was already provided at the orthodontist's. Information about the postoperative period also needs more focus from the dentist performing the extractions. Today many children/adolescents have limited experience of invasive dental treatments, due to good oral health. Tooth extraction prior to orthodontic treatment might therefore be a totally novel experience for the patient. This is perhaps the very first invasive treatment, encounter with local anaesthesia, and possible dental pain for many patients in an otherwise dentally healthy population. It is also important to remember that children are not porcelain figurines. They need to be equipped for reality without sugar coating, instead being honest and preparing them the best way possible.

There was in general a very low demand for pharmaceutical aid to cope with pain. Instead, prevention of pain seems to be the main theme based on data in this study. When formulating guidelines, focus should lie on psychological care.

\section{Conclusions}

Children experience discomfort during and after dental extractions; however, it seems they feel they can cope with it - they are handling the unavoidable unknown. Children want to be well informed about the whole treatment: what to expect before, during, and after the treatment, in this case tooth extractions. With this, they are able to tolerate even some pain/discomfort. It is important that information is 
individually tailored, and given at the right time, to reduce and/or avoid anxiousness prior to the first treatment.

\section{Declarations}

\section{Ethics approval and consent to participate}

Written informed consent for study participation was obtained from the legal guardian. All children received age-appropriate information and consented to participate. The research was conducted ethically in accordance with the World Medical Association Declaration of Helsinki. The Swedish Ethical Review Authority, Sweden (\# 2019-00121, (2018/1029)) approved the study.

\section{Consent for publication}

Not applicable.

\section{Availability of data and materials}

The datasets generated and/or analysed during the current study are not publicly available due to information that could breach patient's confidentiality but are available from the corresponding author on reasonable request.

\section{Competing interests}

The authors declare no conflict of interest. The authors alone are responsible for the content and writing of the paper.

\section{Funding}

This study was supported by grants from the Swedish Dental Society, and research funds from Oral Health Related Research by Region Skåne (Odontologisk Forskning i Region Skåne, OFRS 569491), Sweden. The funders had no role in study design, data collection and analysis, decision to publish, or preparation of the manuscript.

\section{Authors' contributions}

$\mathrm{HB}$ and GK conceived the ideas; KR and DT participated in planning the study and recruiting participants; $\mathrm{HB}$ performed all interviews; $\mathrm{HB}, \mathrm{GK}$ and $\mathrm{UH}$ analysed the data; $\mathrm{HB}$ led the writing, and all authors participated in finalising the manuscript.

\section{Acknowledgements}


The authors express their appreciation to all the informants of this study for taking the time to be interviewed. Also, the authors would like to thank Dr. Anna Alm, DDS, and Dr. Rikard Roxner, DDS, for valuable help with dental extractions on the informants prior their interviews. Finally, our appreciation also goes to Colosseum Smile Dental Group, Malmö City, for their willingness to collaborate regarding this research project.

\section{Authors' information (optional)}

${ }^{1}$ Department of Pediatric Dentistry, Faculty of Odontology, Malmö University, Malmö, Sweden.

${ }^{2}$ Colosseum Smile Dental Group, Malmö, Sweden

\section{References}

1. Berlin H, List T, Ridell K, Davidson T, Toft D, Klingberg G: Postoperative pain profile in 10-15-yr-olds after bilateral extraction of maxillary premolars. Eur Arch Paediatr Dent 2019;20(6):545-55.

2. Ghanei M, Arnrup K, Robertson A. Procedural pain in routine dental care for children: a part of the Swedish BITA study. Eur Arch Paediatr Dent 2018;19(5):365-72.

3. Berlin H, List T, Ridell K, Klingberg G. Dentists' attitudes towards acute pharmacological pain management in children and adolescents. Int J Paediatr Dent 2018;28(2):152-60.

4. Ashley PF, Parekh S, Moles DR, Anand P, MacDonald LC. Preoperative analgesics for additional pain relief in children and adolescents having dental treatment. Cochrane Database Syst Rev 2016;8:CD008392.

5. Berlin H, Vall M, Bergenäs E, Ridell K, Brogårdh-Roth S, Lager E, List T, Davidson T, Klingberg K. Effects and cost-effectiveness of postoperative oral analgesics for additional postoperative pain relief in children and adolescents undergoing dental treatment: Health technology assessment including a systematic review. PLoS One 2019;14(12):e0227027.

6. IASP. International Association for the Study of Pain. 2014.

https://www.iasp-pain.org/Education/Content.aspx?ItemNumber=1698. Updated December 14, 2017. Accessed May 2019.

7. American Academy of Pediatrics. Committee on Psychosocial Aspects of Child and Family Health, Task Force on Pain in Infants, Children, and Adolescents. The assessment and management of acute pain in infants, children, and adolescents. Pediatrics 2001;108(3):793-7.

8. Randall D, Hallowell L. 'Making the bad things seem better': coping in children receiving healthcare. J Child Health Care 2012;16(3):305-13.

9. Glaser BG, Strauss AL. The discovery of grounded theory: strategies for qualitative research. New York: Aldine de Gruyter, 1967.

10. Strauss AL, Corbin J. Basics of qualitative research. Techniques and procedures for developing grounded theory. Thousand Oaks, CA: Sage, 1998. 
11. Charmaz K, Thornberg R, Keane E. Evolving Grounded Theory and Social Justice Inquiry. In: Denzin NK, Lincoln YS, eds. The SAGE Handbook of qualitative research, 5th ed. Thousand Oaks, CA: Sage, 2018;411-43.

12. Hallberg LR. The 'core category' of grounded theory: making constant comparisons. Int J Qual Stud Health Well-being 2006;1:141-8.

13. Blumer H. Symbolic interactionism: perspective and method. Englewood Cliffs, N.J.: Prentice Hall, 1969.

14. Hammersley M. What's wrong with ethnography? Methodological explorations. London: Routledge, 1992.

15. Krekmanova L, Bergius M, Robertson A, Sabel N, Hafström C, Klingberg G, Berggren U. Everyday-and dental-pain experiences in healthy Swedish 8-19 yr olds: an epidemiological study. Int J Paediatr Dent 2009;19(6):438-47.

16. Taddio A, McMurtry CM, Shah V, Riddell RP, Chambers CT, Noel M, MacDonald NE, Rogers J, Bucci LM, Mousmanis P, Lang E, Halperin SA, Bowles S, Halpert C, Ipp M, Asmundson GJG, Rieder MJ, Robson K, Uleryk E, Antony MM, Dubey V, Hanrahan A, Lockett D, Scott J, Bleeker EV; HELPinKids\&Adults. Reducing pain during vaccine injections: clinical practice guideline. CMAJ 2015;187(13):975-82.

17. Klingberg G, Arnrup K. Dental Fear and Behavior Management Problems. In: Koch G, Poulsen S, Espelid I, Haubek D, eds. Pediatric dentistry: a clinical approach. 3rd edition. Chichester, West Sussex, UK: Wiley-Blackwell, 2017.

18. ten Berge M. Dental fear in children: clinical consequences. Suggested behaviour management strategies in treating children with dental fear. Eur Arch Paediatr Dent 2008;9(Suppl 1):41-46.

19. Prins JM. Anxiety in medical settings. In: Ollendick TH, King NJ, Yule W, eds. International Handbook of Phobic and Anxiety Disorders in Children and Adolescents. [electronic resource] [Internet]. 1st ed. 1994. Springer US; 1994 [cited 2020 Jun 4].

20. Davies EB, Buchanan H. An exploratory study investigating children's perceptions of dental behavioural management techniques. Int J Paediatr Dent 2013;23(4):297-309.

21. Melamed BG, Dearborn M, Hermecz DA. Necessary considerations for surgery preparation: age and previous experience. Psychosom Med 1983;45(6):517-25.

22. Hembrecht EJ, Nieuwenhuizen J, Aartman IH, Krikken J, Veerkamp JS. Pain-related behaviour in children: a randomised study during two sequential dental visits. Eur Arch Paediatr Dent 2013;14(1):3-8.

23. Ollendick TH, King NJ. Origins of childhood fears: an evaluation of Rachman's theory of fear acquisition. Behav Res Ther 1991;29(2):117-23.

24. Davey GC. Dental phobias and anxieties: evidence for conditioning processes in the acquisition and modulation of a learned fear. Behav Res Ther 1989;27(1):51-8.

25. de Jongh A, Muris P, ter Horst G, Duyx MP. Acquisition and maintenance of dental anxiety: the role of conditioning experiences and cognitive factors. Behav Res Ther 1995;33(2):205-10. 
26. ten Berge M, Veerkamp JS, Hoogstraten J. The etiology of childhood dental fear: the role of dental and conditioning experiences. J Anxiety Disord 2002;16(3):321-9.

27. Rodd H, Timms L, Noble F, Bux S, Porritt J, Marshman Z. 'Message to Dentist': Facilitating Communication with Dentally Anxious Children. Dent J (Basel) 2019;7(3):69.

28. Van Meurs P, Howard KE, Versloot J, Veerkamp JS, Freeman R. Child coping strategies, dental anxiety and dental treatment: the influence of age, gender and childhood caries prevalence. Eur $\mathrm{J}$ Paediatr Dent 2005;6(4):173-8.

29. Hill CE, Thompson BJ, Williams EN. A guide to conducting consensual qualitative research. Couns Psychol 1997;25(4):517-72.

30. Hill CE, Knox S, Thompson BJ, Williams EN, Hess SA, Ladany N. Consensual qualitative research: An update. J Couns Psychol 2005;52(2),196-205.

31. Morse J. Reframing Rigor in Qualitative Inquiry. In: Denzin NK, Lincoln YS, eds. The SAGE Handbook of Qualitative Research, 5th ed. Thousand Oaks, CA: Sage, 2018;796-817.

32. Bolderston A. Conducting a research interview. J Med Imaging Radiat Sci 2012;43(1):66-76. 